\title{
OVERWEIGHT AND HYPERTENSION AMONG COLLEGE OF HEALTH SCIENCES EMPLOYEES IN GHANA
}

$$
\text { Aryeetey } \mathbf{R}^{1^{*}} \text { and } \mathbf{J} \text { Ansong }{ }^{2}
$$

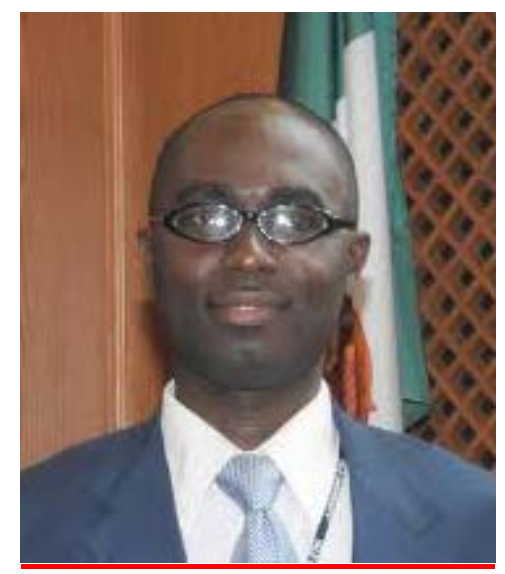

\section{Richmond Aryeetey}

*Corresponding author email: raryeetey@ug.edu.gh

${ }^{1}$ School of Public Health, University of Ghana, P.O. Box LG 13, Legon, Accra

${ }^{2}$ Health Concern Ghana, West Legon, Accra 


\section{ABSTRACT}

Healthcare workers, by virtue of their greater access to information, are expected to have less risk of obesity, hypertension, and other health outcomes often linked to lifestyles. However, there is limited evidence on practices and status of personnel who work in the healthcare setting about hypertension and overweight in Ghana. The current study tests the hypothesis that overweight and hypertension rates, as well as related risk factors among staff and faculty of the College of Health Sciences (CHS), University of Ghana, will be more positive than among the lay public. In June and July 2009, a cross-sectional self-completed survey was administered to 141 male and female faculty and staff of the College of Health Sciences, University of Ghana, in Accra. A representative sample was selected by proportionate random sampling from all seven academic and research units of the CHS. Anthropometry and blood pressure measurements were taken with questionnaire data on lifestyle, dietary history, and socio-demographic variables. Overweight and obesity were diagnosed as BMI >25 and $>30 \mathrm{~kg} / \mathrm{m}^{2}$, respectively. Abdominal adiposity was estimated as waist hip ratio $>0.80$ (females) or $>0.95$ (males). Hypertension was diagnosed as diastolic or systolic blood pressure $>140$ or $90 \mathrm{~mm}$ Hg, respectively. Mean age of respondents was $40.5 \pm$ 10.8 years; $43 \%$ were over-weight, including $13 \%$ obese. More than one-third of overweight respondents did not report an overweight body image. Abdominal adiposity and hypertension rates were $25 \%$ and $34 \%$, respectively. Low rates of regular physical activity (25\%) and consumption of fruits and vegetables (40\%) were observed. Overweight $(\mathrm{OR}=3.83 ; \mathrm{p}<0.01)$ and central adiposity $(\mathrm{OR}=4.8 ; \mathrm{p}<0.01)$ were associated with significantly increased risk of hypertension. Being married was a significant predictor of overweight $(\mathrm{p}<0.05)$, abdominal adiposity $(\mathrm{p}<0.05)$, and hypertension $(\mathrm{p}<0.05)$. The study concludes that working in a healthcare environment or being a health worker does not diminish your risk of overweight and hypertension. It is, therefore, recommended that interventions addressing overweight and hypertension should place attention more on environmental modifications rather than awareness creation.

Key words: Overweight, hypertension, abdominal adiposity, lifestyle 


\section{INTRODUCTION}

Overweight and related co-morbidities such as hypertension and diabetes are emerging as important public health challenges in Ghana [1, 2]. Among urbandwelling women in Ghana's capital city, Accra, overweight prevalence has been estimated to be in excess of $61 \%$, including $34 \%$ obese [3]. The latest Demographic and Health Survey (DHS), based on nationally representative data, reported $30 \%$ overweight (including 9\% obesity) among 15-49 year old Ghanaian women [4]. The 2008 DHS also demonstrated that the overweight prevalence in urban communities was about twice that in rural communities.

A recent review of the existing literature reported hypertension prevalence ranging between $19-45 \%$, and reaching as high as $55 \%$ in one study [2]. Routine public health data also show that hypertension has moved up to become a part of the top five reported ailments in most regions in Ghana [5], and possibly at a greater rate in urban areas like Accra [6]. Altogether, the evidence is suggestive of an increasing rate of diagnosis of new hypertension cases. A study among residents in Kumasi, the second largest city in Ghana reported that only about a third of the people with elevated blood pressure were aware of their conditions [7].

A highly motivated public health service initiative is thus needed to address the rapidly emerging burden of chronic disease in Ghana. However, little is known about the health status as well as lifestyles of health professionals in Ghana. The current preliminary study was designed to determine the prevalence of overweight and hypertension among faculty and staff of the College of Health Sciences (CHS) in Accra. In addition, considering that personnel of the CHS have greater access to information and services, the study tested the hypothesis that they will have optimal body weight and blood pressure as well as report behaviors consistent with their optimal health status.

\section{METHODS}

In June 2009, a cross-sectional study was conducted on the Korle-Bu and Legon Campuses of the University of Ghana. The study included personnel of the CHS. The CHS which consists of seven research and academic sub-units had a total of 1,114 employees, at the time of the survey. The employees were appointed as Junior Staff, Senior Staff, or Senior Members. Senior Members included teaching and research faculty as well as senior level administrative personnel. Senior and Junior Staff included all other personnel at various levels of research and administrative appointment.

All CHS personnel from the seven sub-units were eligible to participate in the study. The total 142 study participants were selected using a proportionate random sampling procedure that included more respondents from larger CHS units, with the aid of random number statistical tables. For each sub-unit, a fixed number of respondents assigned by proportion were selected from the list of potential respondents in that 
subunit. Selected personnel who refused or were unavailable to participate were replaced with others from their sub-unit.

Questionnaires were self-completed by respondents. The questionnaires collected data on socio-demographic characteristics, personal and familial health history, health risk behavior (alcohol consumption and smoking), nutrition knowledge, habitual dietary consumption behavior, and physical activity. A food frequency questionnaire and a 24-hour dietary recall tool were used to describe respondents' habitual and recent dietary intake, respectively. Physical activity was assessed using a modified version of the international physical activity questionnaire [8]. Respondent body weight, height, waist and hip circumferences as well as diastolic and systolic blood pressure were measured using standard methods [9, 10]. Dietary knowledge was assessed using questions on nutrient content in commonly eaten foods and their risk for overweight and other chronic diseases.

Anthropometric and blood pressure measurements were performed at a central location in each sub-unit. Trained personnel used a portable Sea electronic floor scale (Sea Precision Weighing Balances, Bradford, USA), with a precision of $0.1 \mathrm{~kg}$, to measure the weight of respondents. Height was measured without shoes to the nearest $0.1 \mathrm{~cm}$ using a Shirr board (Shirr productions, Marvland, USA). Waist and hip circumferences were measured to the nearest $1 \mathrm{~mm}$ using a non-stretchable fibre-glass measuring tape (Butterfly, China). All anthropometric measurements were performed in replicate, and independently on each respondent by two trained personnel. In the case where the difference in measurements exceeded allowable acceptable limits, the measurements were repeated. Blood pressure was measured on the left arm, with the respondent sitting down, and after a five minutes rest, using a mercury sphygmomanometer (Accoson-MK.3, A.C. Cossor and Son [Surgical] Ltd, England). Replicate blood pressure measurements were taken 10 minutes apart, to the nearest $5 \mathrm{~mm} \mathrm{Hg}$. The mean of the two measurements was used as the estimate for systolic and diastolic blood pressure measures.

The study was approved by the Ghana Health Service Ethical Committee. Additionally, permission was granted by the Registrar of the College to implement the study.

Data analysis was performed using SPSS version 15 (SPSS Inc, Chicago). Overweight and obesity were defined as body mass index (BMI) $\geq 25 \mathrm{~kg} / \mathrm{m}^{2}$ and $\geq 30 \mathrm{~kg} / \mathrm{m}^{2}$, respectively [9]. Abdominal adiposity was defined as waist-hip ratios (WHR) $>0.80$ for females and $>0.95$ for males [10]. Hypertension was diagnosed as mean elevated systolic or diastolic blood pressure in excess of 140 or $90 \mathrm{~mm} \mathrm{Hg}$ or both, as described by Addo and collegues [11]. Logistic regression modeling was used to identify risk factors associated with obesity and hypertension, controlling for lifestyle, sociodemographic and dietary characteristics. 


\section{FINDINGS}

A total of 141 respondents including 33\% females completed the survey (Table 1). Mean age of respondents was $40.5 \pm 10.8$ years and about half of respondents (52\%) were at least 40 years old. Almost two-thirds (62\%) of respondents were married and two-thirds lived in households with five or less members. Table 1 also reports details of lifestyle characteristics, and dietary history. About one-quarter of respondents (24.8\%) reported a lifestyle that involved at least three times of moderate or vigorous physical activity in the last 7 days. Consumption of fruit and vegetables for at least 5 times in a week was reported among only $40 \%$ of respondents.

\section{Overweight and Obesity}

Table 2 shows the rate of overweight among respondent categories. Based on BMI analysis, $43 \%$ of respondents were over-weight, including $13 \%$ who were obese. Among those who did not consider themselves overweight, $37 \%$ and $11 \%$ were diagnosed (based on BMI analysis) as overweight and obese, respectively. The risk of overweight increased with age (Table 3) and also, was greater among Senior Members (OR=2.9; 95\% CI: 1.2, 5.9) and Senior Staff (OR=2.7; 95\% CI: 1.2, 7.1), compared to Junior Staff. Additionally, being married was associated with increased risk of overweight $(\mathrm{OR}=2.9 ; 95 \% \mathrm{CI}$ : 1.4, 6.0). Intake of alcohol for more than 3 times a week was associated with increased risk of obesity (OR=4.7; 95\% CI: 1.2, 18.2; data not shown). Abdominal adiposity was observed among $25 \%$ of respondents (Table 2). Prevalence of central adiposity among married respondents (32\%) was more than twice that among the unmarried (15\%), representing a greater risk $(\mathrm{OR}=2.7 ;$ 95\% CI: 1.1, 6.5) among married respondents.

\section{Hypertension}

The current study estimated hypertension prevalence at 34\% (Table 2). Less than half (44\%) of those diagnosed hypertensive were aware of their status. Fifteen percent had been previously diagnosed with hypertension. All respondents with previous hypertension diagnosis reported that they were taking anti-hypertensive medication although none had their hypertension under control (Table 2).

Risk of hypertension increased with age (OR=1.09; 95\% CI: 1.05, 1.1). The highest prevalence of hypertension was observed among respondents who were married (43\%), male (40\%), senior members $(43 \%)$, or overweight $(51 \%)$. Statistically significant associations were observed between hypertension and being married $(\mathrm{OR}=2.9$; 95\% CI: 1.3, 6.3), alcohol intake of at least 4 times per week (OR=6.0; 95\% CI: $1.5,23.8)$, abdominal adiposity (OR=6.7; 95\% CI: 2.9, 15.5; data not shown), and overweight (OR=3.8; 95\% CI: 1.8, 8.0; data not shown). Among hypertensive respondents, one-third was obese and two-thirds were overweight. Half (50\%) of those diagnosed with hypertension were also diagnosed with abdominal adiposity. The prevalence of co-existing obesity, central adiposity, and hypertension was $13 \%$ and about $8 \%$ had co-existence of overweight, central adiposity, and hypertension. Co-morbidity of overweight, central adiposity, and hypertension was not different across sexes but was more likely among married respondents (OR=3.8; 95\% CI: 1.1, 13.8). Respondents who consumed any amount of alcohol at least, 4 times per week, 


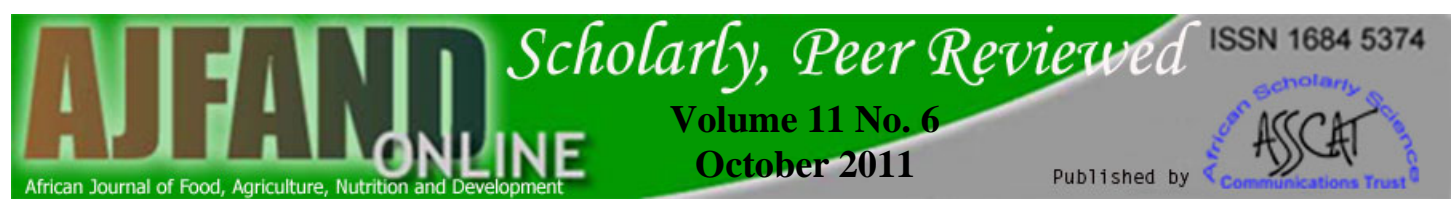

had a greater risk of co-morbidity involving overweight, central adiposity and hypertension (OR=4.4; 95\% CI: 1.1, 16.7).

\section{DISCUSSION}

The current study reports overweight and hypertension prevalences of $43 \%$ and $34 \%$, respectively among employees of the CHS. The most interesting finding of the current study is that the overweight and hypertension rates among this group, which includes highly educated health professionals, teachers, and other staff who work with them on a daily basis are not different from those reported for the general population in earlier studies in Ghana. Concerning hypertension, a recent review of earlier studies reported hypertension prevalence ranging between 19\% and 48\%, across studies [2]. The 2008 Demographic and Health survey reported that about 30\% of women ages 15 to 49 years were either overweight or obese [3]. In urban Accra, 52\% overweight or obesity was reported among women participating in a large survey [4].

Based on their education and opportunities for acquiring healthy behavior change information, CHS staff and faculty could be expected to have better outcomes and lifestyle indicators than the general public. However, the current findings do not support this assumption. The findings of the study should, however, be interpreted with consideration for the ecological determinants of overweight and hypertension, which may act independent of knowledge and personal habits. College of Health Sciences employees living in Accra are exposed to similar ecological risk factors (changing food environment, limited opportunities for physical activity, and workrelated stress) as other city dwellers. An important implication of the findings is that being exposed to an environment (such as a health training institution) where there is greater exposure to health information and experts, or even being a health care worker) may not diminish an individual's risk to overweight and hypertension. This finding illustrates the significant role the immediate environment plays in modifying behavior.

Although overweight prevalence was high among this relatively highly educated segment of the population, most of those who were diagnosed as overweight or obese did not consider themselves as having an overweight image. Studies have reported denial as a common phenomenon among overweight males and females [12-13], similar to what was observed in the current study. One reason why overweight persons adopt denial is because public perception of overweight is stigmatizing [14] and is thus associated with psychosocial distress. Another explanation is that because overweight is common, it stands the chance of becoming the normative reference, rather than an exception, in the population.

Duda and colleagues [15] have reported that while all Ghanaian women would like to reduce their current body image to a smaller, healthier body image, obese women were even more likely to make that choice. Contrary to popular belief, Jumah and Duda [16] have also reported that both male and female Ghanaians identify a normal body weight their ideal body image. Health promotion interventions should, therefore, 
anticipate that many overweight persons may not seek services because of status denial even though they will prefer to address overweight in order to be healthy.

The current study also points to the limited knowledge of the health status of health care providers and other professionals involved in training health workers in Ghana. This category of the population is an important group of interest because, they are naturally expected by the lay public to lead the way in practicing healthy lifestyles. Elsewhere, studies show that health workers may not be different from their patients in their practice of healthy lifestyles [17]. Also, health professionals who engage in healthy lifestyles regularly are more likely to promote adoption of such behaviors among their clients $[18,19]$.

Among the study participants, physical activity frequency was low, reflecting the increasingly sedentary lifestyle of urban residents. Few studies have reported physical activity data among Ghanaian adults [20,21]. The 2008 DHS reported on physical activity among both males and females, indicating that, about half of women and a quarter of men did not perform any vigorous intensity physical activity, during the week preceding the survey. Low physical activity frequency and intensity is associated with overweight and related chronic disease outcomes [22]. In addition, consumption of fruits and vegetables was low among respondents in this study. This is not surprising. In 2009, the World Health Organization reported that more than onethird of Ghanaians had low fruit and vegetable intake [23]. The relative high cost of fruits and vegetables in Ghana [24] may partly explain the low consumption. The 2008 DHS shows that high frequency of fruit consumption per week was associated with wealth status [4]. The relatively greater accessibility to non-fruit snacks such as pastries may explain the low fruit consumption among this category of urban dwellers. The bottom line, however, is that workers in healthcare training environment were not motivated to practice healthy lifestyles anymore than the lay public.

Emerging trends of overweight and diet-related chronic diseases in Ghana warrant both ecological and intra-personal interventions that promote optimal dietary practices as part of a broader intervention strategy to address overweight and related conditions [25]. Currently, there is no national policy framework to guide healthy dietary practices and this is urgently needed. Interventions that address the clinical aspects of over-nutrition are also warranted to enable currently overweight persons to be able to access care, whenever they need it. In addition, preventive strategies should focus less on improving population level awareness and risk perception, and instead, place emphasis on modifying the food and physical activity environment.

\section{IMPLICATIONS FOR RESEARCH AND PRACTICE}

The current study shows that among staff of the College of Health Sciences, overweight and hypertension prevalence was high and not different from rates observed among the general urban-dwelling public. The study also found low levels of healthy living behavior, despite greater awareness of risk among health workers. For future interventions to be effective, their design must employ actions that do not

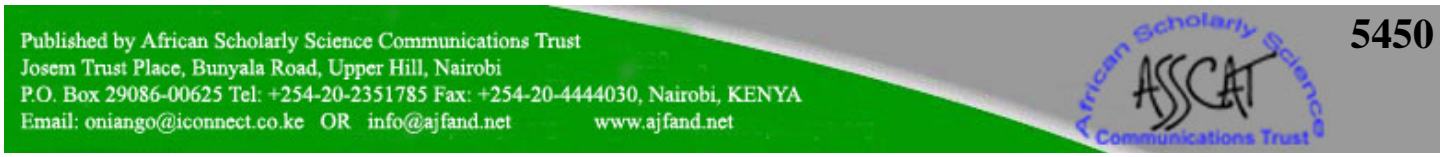


depend on individuals' personal responsibility for adoption. Environmental modifications, legislation and policies that require minimal individual responsibility may likely achieve greater success and should be given adequate attention. The current study provides a basis for testing environment-based interventions to address overweight and hypertension among health professionals in practice, in Ghana.

\section{AUTHORS' CONTRIBUTIONS}

The study was conceived by Richmond Aryeetey who also carried out the statistical analysis and drafting of the manuscript while Joanna Ansong designed the data collection tools and implemented the data collection. Data cleaning and entry was performed by Joanna Ansong.

\section{ACKNOWLEDGEMENT}

We acknowledge the support given by the Ghana Health Service Nutrition Department, including providing equipment for the anthropometric assessments. We also appreciate all respondents who took time off their work to respond to the survey. 


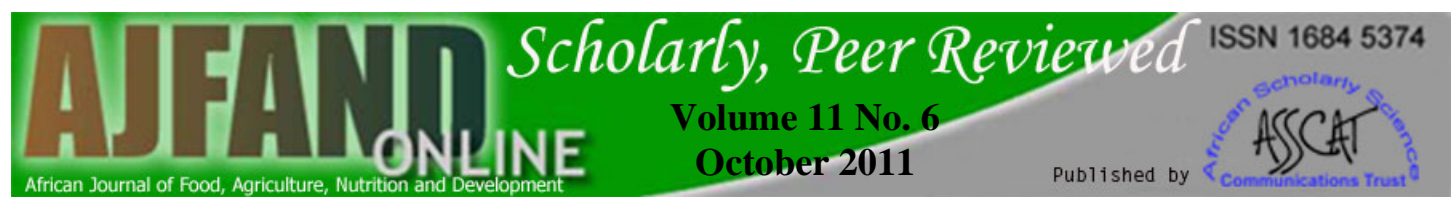

Table 1: Characteristics of Faculty and Staff in the College of Health Sciences, $(n=141)$

\begin{tabular}{|c|c|c|c|}
\hline Characteristics & Male & Female & Total \\
\hline \multicolumn{4}{|l|}{ Socio-demographic } \\
\hline Age, $y$ & $41.9 \pm 11.2^{£}$ & $37.6 \pm 9.5$ & $40.5 \pm 10.8$ \\
\hline Educational experience, y & $14.5+5.0$ & $14.8 \pm 4.4$ & $14.6 \pm 4.9$ \\
\hline Married & $67.4(64)^{¥}$ & $50.0(23)$ & $61.7(87)$ \\
\hline \multicolumn{4}{|l|}{ Household size } \\
\hline $1-5$ & $56.8(54)$ & $7601(34)$ & $63.1(89)$ \\
\hline $6+$ & $43.2(41)$ & $23.9(11)$ & $36.9(52)$ \\
\hline \multicolumn{4}{|l|}{ Rank } \\
\hline Senior Member & $22.1(21)$ & $15.2(7)$ & $19.9(28)$ \\
\hline Senior Staff & $22.1(21)$ & $41.3(19)$ & $28.4(40)$ \\
\hline Junior Staff & $55.8(53)$ & $43.5(20)$ & $51.8(73)$ \\
\hline \multicolumn{4}{|c|}{ Duration of employment with CHS, y } \\
\hline $1-2$ & $20.2(19)$ & $19.6(9)$ & 20.0 \\
\hline $3-5$ & $19.1(18)$ & $28.3(13)$ & 22.1 \\
\hline $6+$ & $60.6(57)$ & $52.2(24)$ & 57.9 \\
\hline \multicolumn{4}{|l|}{ Lifestyle risk factors } \\
\hline $\begin{array}{l}\text { physical activity (3x per week or } \\
\text { more) }\end{array}$ & $31.6(30)$ & $10.9(5)$ & $24.8(35)$ \\
\hline Daily Sitting duration, hr & $5.4 \pm 1.7$ & $6.5 \pm 1.3$ & $5.8 \pm 1.6$ \\
\hline Feels stressed almost daily & $8 . \overline{4}(8)$ & $10 . \overline{9}(5)$ & $9.2(13)$ \\
\hline $\begin{array}{l}\text { alcoholic beverage intake }>3 \\
\text { times/wk }\end{array}$ & $11.6(7)$ & 0 & $7.8(11)$ \\
\hline Ever smoking & $22.1(21)$ & 0 & $14.9(21)$ \\
\hline Overweight self image & $13.7(13)$ & $15.2(7)$ & $14.2(20)$ \\
\hline Perceived overweight by friends & $18.9(18)$ & $10.9(5)$ & $16.3(23)$ \\
\hline Prior hypertension diagnosis & 18.9(18) & $6.5(3)$ & $14.9(21)$ \\
\hline \multicolumn{4}{|l|}{ Family health history } \\
\hline At least one parent overweight & $17.6(16)$ & $28.9(13)$ & $21.3(29)$ \\
\hline At least one parent diabetic & $1.2(1)$ & $16.7(7)$ & $6.5(8)$ \\
\hline At least one parent hypertensive & $31.0(26)$ & $29.5(13)$ & 30.5 (39) \\
\hline \multicolumn{4}{|l|}{ Dietary habits } \\
\hline$\overline{\text { Dietary knowledge score }}$ & $6.4 \pm 1.9$ & $6.8 \pm 1.9$ & $6.5 \pm 1.9$ \\
\hline Weekday meal frequency & $2.4(2.6,2.6)$ & $2.4(2.2,2.6)$ & $2.3(2.2,2.5)$ \\
\hline Weekend meal frequency & $2.5(2.3,2.7)$ & $2.3(2.1,2.5)$ & $2.5(2.3,2.6)$ \\
\hline $\begin{array}{l}\text { Almost daily intake of fruit and } \\
\text { vegetable }\end{array}$ & $37.9(36)$ & $43.5(20)$ & $39.7(56)$ \\
\hline Snacking at least twice daily & $13.7(13)$ & $10.9(5)$ & $12.8(18)$ \\
\hline
\end{tabular}

$¥=\%$ (n);

$\mathbf{E}=$ arithmetic mean \pm standard deviation 


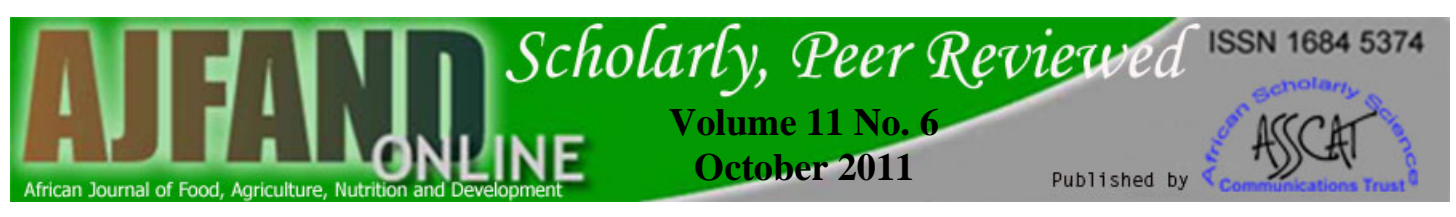

Table 2: Body composition and hypertension among College faculty and staff in Ghana (n=141)

\begin{tabular}{|c|c|c|c|c|}
\hline \multirow[t]{2}{*}{ Characteristics } & \multicolumn{3}{|c|}{ Body composition } & \multirow[t]{2}{*}{ Hypertension $^{\S}$} \\
\hline & $\mathrm{BMI} \geq 25 \mathrm{~kg} / \mathrm{m}^{2}$ & $\mathrm{BMI} \geq 35 \mathrm{~kg} / \mathrm{m}^{2}$ & $\begin{array}{c}\text { Elevated Waist-hip } \\
\text { ratio }^{\epsilon}\end{array}$ & \\
\hline \multicolumn{5}{|l|}{ Employment rank } \\
\hline Senior member & $57.1(16)^{\mathbf{q a},}$ & $17.9(5)$ & $21.4(6)$ & $42.9(12)$ \\
\hline Senior staff & $55.0(22)^{\mathbf{a}, \mathbf{b}}$ & $15.0(6)$ & 32.5 (13) & $30.0(12)$ \\
\hline Junior staff & $31.5(23)^{c}$ & $9.6(7)$ & $23.3(17)$ & $32.9(24)$ \\
\hline \multicolumn{5}{|l|}{ Sex } \\
\hline Males & $41.1(39)$ & $11.6(11)$ & $27.4(26)$ & $40.0(38)$ \\
\hline Females & $47.8(22)$ & $15.2(7)$ & $21.7(10)$ & $21.7(10)$ \\
\hline \multicolumn{5}{|l|}{ Age groups, y } \\
\hline $20-29$ & $18.5(5)$ & 0 & 0 & $11.1(3)$ \\
\hline $30-39$ & $46.3(19)$ & $17.1(7)$ & $26.8(11)$ & $22.0(9)$ \\
\hline $40-49$ & $53.2(21)$ & $10.3(4)$ & $25.6(10)$ & $41.0(16)$ \\
\hline $50+$ & $47.1(16)$ & $20.6(7)$ & $44.1(15)$ & $58.8(20)$ \\
\hline \multicolumn{5}{|l|}{ Marital status } \\
\hline Married & $52.9(46)^{\mathbf{a}}$ & $16.1(14)$ & $32.2(28)$ & $42.5(37)$ \\
\hline Not married & $27.8(15)^{\mathbf{b}}$ & $7.4(4)$ & $14.8(8)$ & $20.4(11)$ \\
\hline \multicolumn{5}{|c|}{ Self-perceived overweight } \\
\hline Yes & $80.0(16)$ & $25.0(5)$ & $35.0(7)$ & $60.0(12)$ \\
\hline No & $37.2(45)$ & $10.7(13)$ & 24.0 (29) & $29.8(36)$ \\
\hline \multicolumn{5}{|c|}{$\begin{array}{l}\text { On anti-hypertensive } \\
\text { treatment }\end{array}$} \\
\hline Yes & $66.7(14)$ & $23.8(5)$ & $47.6(10)$ & $100.0(21)$ \\
\hline No & 39.2 (47) & 10.8 (13) & 21.7 (26) & - \\
\hline Total & $43.3(61)$ & $12.8(18)$ & $25.5(36)$ & 34.0 (48) \\
\hline
\end{tabular}

$¥=\%$ (n); $€=$ Waist-hip-ratio $>0.9$ for men and $>0.85$ for women; $\S=$ systolic and diastolic blood pressure $>140 / 90$ or taking antihypertensive medication 


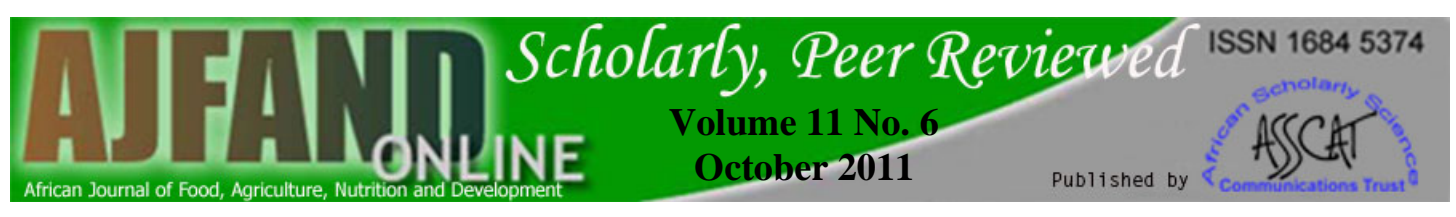

Table 3: Univariate Determinants of Overweight and Hypertension among College Staff and Faculty in Ghana.

\begin{tabular}{|c|c|c|c|}
\hline \multirow[t]{2}{*}{ Determinants } & \multicolumn{3}{|c|}{ Crude Odds Ratio (95\% Confidence Intervals) } \\
\hline & $\mathrm{BMI} \geq 25 \mathrm{~kg} / \mathrm{m}^{2}$ & Elevated Waist-hip ratio ${ }^{\epsilon}$ & Hypertension $^{\S}$ \\
\hline \multicolumn{4}{|l|}{ Employment rank } \\
\hline Junior Staff & 1 & & \\
\hline Senior Staff & $2.7(1.2,5.9)^{*}$ & & \\
\hline Senior member & $2.9(1.2,7.1)^{*}$ & & \\
\hline \multicolumn{4}{|l|}{ Sex } \\
\hline Males (reference) & & & 1 \\
\hline Females & & & $0.4(0.2,0.9)^{*}$ \\
\hline \multicolumn{4}{|l|}{ Age groups, $\mathrm{y}$} \\
\hline 20-29 (reference) & 1 & & 1 \\
\hline $30-39$ & $3.8(1.2,12.0)^{*}$ & & $2.6(0.5,9.2)$ \\
\hline $40-49$ & $5.1(1.6,16.3)^{* *}$ & & $5.6(1.4,21.7)^{*}$ \\
\hline $50+$ & $3.9(1.2,12.7)^{*}$ & & $11.4(2.9,45.5)^{* *}$ \\
\hline \multicolumn{4}{|l|}{ Alcohol intake $(\geq 4 \mathrm{x} / \mathrm{wk})$} \\
\hline No (reference) & & & 1 \\
\hline Yes & & & $6.0(1.5,23.8)^{*}$ \\
\hline \multicolumn{4}{|l|}{ Current marital status } \\
\hline Not married (reference) & 1 & 1 & 1 \\
\hline Married & $2.9(1.4,6.0)^{* *}$ & $2.7(1.1,6.5)^{*}$ & $2.9(1.3,6.3)^{* *}$ \\
\hline \multicolumn{4}{|l|}{ Considers self overweight } \\
\hline No (reference) & 1 & & 1 \\
\hline Yes & $6.8(2.1,21.5)^{* *}$ & & $3.5(1.3,9.4)^{*}$ \\
\hline
\end{tabular}




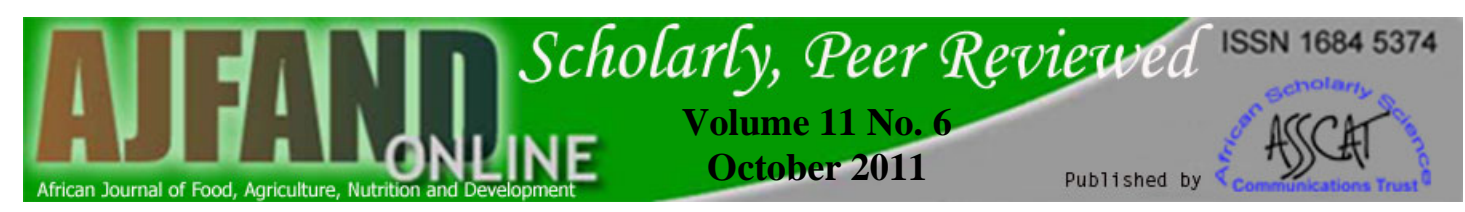

\section{REFERENCES}

1. de-Graft Aikins A Ghana's neglected chronic disease epidemic: a developmental challenge. Gh. Med. J. 2007; 41:154-159.

2. Bosu WK Epidemic of Hypertension in Ghana: A systematic review. BMC Public Health 2010; 10:418.

3. Hill AG, Darko R, Seffah J, Adanu RMK, Anarfi JK and RB Duda Health of urban Ghanaian women as identified by the Women's Health Study of Accra. Int. J. Gynecol. Obstet. 2007; 99:150-156.

4. Ghana Statistical Service (GSS), Ghana Health Service (GHS) and ICF Macro. Ghana Demographic and Health Survey 2008. GSS, GHS, and ICF Macro, Accra, Ghana, 2009.

5. Centre for Health Information Management. Outpatient morbidity in health facilities. Ghana Health Services, Accra Ghana, 2008.

6. Greater Accra Regional Health Directorate. Annual Report 2007. Ghana Health Services Accra Ghana, 2008.

7. Agyemang C, Bruijnzeels MA and E Owusu-Dabo Factors associated with hypertension awareness, treatment, and control in Ghana, West Africa. $J$. Human. Hypert. 2006; 20:67-71.

8. Ainsworth BE, Macera CA, Jones DA, Reis JP, Addy CL, Bowles HR and HW Kohl Comparison of the 2001 BRFSS and the IPAQ Physical Activity Questionnaires. Med. Sci. Sports. Exerc. 2006;38:1584-92.

9. Cogill B Anthropometric Indicators Measurement Guide. Food and Nutrition Technical Assistance Project, Academy for Educational Development, Washington, D.C.2003.

10. U.S. Department of Agriculture and U.S. Department of Health and Human Services Dietary Guidelines for Americans, 3rd edition, Government Printing Office: Washington, DC, US, 1990.

11. Addo J, Smeeth $\mathbf{L}$ and DA Leon Prevalence, detection, management, and control of hypertension in Ghanaian civil servants in Ghana. Ethn. \& Dis. 2008; 18:505-511

12. DeVille-Almond J, Tahrani AA, Grant J, Gray M, Thomas GN and S Taheri Awareness of obesity and diabetes: a survey of a subset of British male drivers. Am. J. Mens. Health. 2011; 5:30-7.

13. Mahbubur R and AB Berenson Self-Perception of Weight and Its Association With Weight-Related Behaviors in Young Reproductive-Aged Women. Obstet \& Gynecol 2010; 116:1274-1280. 
14. Puhl RM amd KD Brownell Bias, discrimination, and obesity. Obes. Res. 2001; 9:788- 905.

15. Duda RB, Jumah NA, Hill AG, Seffah J and R Biritwum Interest in healthy living outweighs presumed cultural norms for obesity for Ghanaian women. Health and Qual. of Life Outcomes 2006; 4:44.

16. Jumah NA and RB Duda Comparison of the perception of ideal body images of Ghanaian men and women. Afr. J. Health Sci. 2007; 14:54-60.

17. McNerney JP, Andes S and DL Blackwell Self-reported health behaviors of osteopathic physicians. J. Am. Osteopath. Assoc. 2007;107:537-46.

18. Clever LH and GM Arsham Physicians' own health-some advice for the advisors. West J. Med. 1984 ;141(6):846-54.

19. Frank E, Rothenberg R, Lewis C and BF Belodoff Correlates of Physicians' Prevention-Related Practices: Findings from the Women Physicians' Health Study. Arch. Fam. Med. 2000; 9:359-367.

20. Amoah AGB Sociodemographic variations in obesity among Ghanaian adults. Public Health Nutr. 2003; 6: 751-757

21. Biritwum RB, Gyapong $\mathbf{J}$ and $\mathbf{G}$ Mensah The Epidemiology of Obesity in Ghana. Gh. Med. J. 2005; 39: 82-85.

22. World Health Organization (WHO) Global Recommendations of Physical Activity for Health. WHO, Geneva, 2010.

23. Hall JN, Moore S, Harper SB and JW Lynch Global variability in fruit and vegetable consumption. Am. J. Prev. Med. 2009; 36:402-409.

24. Ruel MT, Minot $\mathbf{N}$ and $\mathbf{L}$ Smith Patterns and Determinants of Fruit and Vegetable consumption in Sub-Saharan Africa: A Multicountry comparison. WHO, Geneva, 2005.

25. World Health Organization (WHO) Global Strategy on Diet, Physical Activity and Health. WHO, Geneva, 2004. 